\title{
Relationship between Sociodemographics, Dietary Intake , Activities of Daily Living and Gestational Weight among Pregnant women in a Rural Areal
}

\author{
Rania E.El-Gobashy ${ }^{1}$, Dalal K.Eshra ${ }^{2}$, Inas k.Aly ${ }^{3}$ \\ ${ }^{23}$ Professor of maternal and new born health nursing, Faculty of Nursing, Menoufia \\ University
}

\begin{abstract}
Gestational weight gain (GWG) is a determinant of health and nutrition of mothers and offspring. However many factors associated with GWG are not completely understood .The aim of the current study was to assess the relationship between sociodemographics, dietary intake and activity of daily living with gestational weight among pregnant women in a rural area. The Design of this study was descriptive study . All eligible pregnant women who met inclusion criteria (324) were included. Instruments of this study included socio-demographic characteristics, data about current pregnancy and labor, data about current dietary intake, and data about activities of daily living. The findings revealed that Women gained an average of $12.87 \mathrm{~kg}$ during pregnancy while $54 \%$ did not gain weight within the Institute of Medicine (IOM)-recommended range. Univariate logistic models showed that gestational weight gain was related to age, prepregnancy body mass index (BMI), energy intake, and sitting time. Cumulative logit model showed positive relationship between age $(\mathrm{p}=0.0137)$ and pre-pregnancy BMI $(\mathrm{p}<0.0001)$ with GWG. It is concluded that, there was positive relationship between maternal characteristics such as age, pre-pregnancy basal metabolic index, energy intake and taking care of children with gestational weight gain As inadequate or excessive prenatal weight gain could have adverse effects on both mother and child there is a need to inform pregnant women to gain appropriate amount of weight during pregnancy. It is recommended that pregnant women should be advised on achieving the recommended gestational weight gain to prevent adverse maternal and prenatal outcomes.
\end{abstract}

Key words: Dietary intake; Gestational weight gain, Activities of daily living

\section{Introduction}

Gestational weight gain (GWG) within the Institute of Medicine (IOM)-recommended range is associated with improved maternal and neonatal outcomes compared to weight gain lower or higher than these recommendations. Low weight gain during pregnancy is associated with small-forgestational age, low birth weight, and preterm birth of the baby (Yekta et al, 2013).

In contrast, high GWG is related to several complications in mothers, such as hypertension, diabetes, pre-eclampsia, macrosomia, and maternal weight retention postpartum. In additon, GWG may also influence body composition in childhood and later life. (Helms et al ., 2010). Studies have also suggested that excessive GWG is associated with higher fat mass in childhood and greater body mass index (BMI) and fat mass in later adulthood (Chen et al., 2013 ).

In the developing countries, women generally have a lower GWG than women in the developed countries. Several studies in the United States and Europe reported that the mean GWG was in the range of 13$14.2 \mathrm{~kg}$. (Burnett et al.,2012). Ota et al., (2013) reported that GWG among women with mean age $27.9 \pm 5.3$ years) in Vietnam was $12.2 \mathrm{~kg}$. The researchers also reported that about $40 \%$ of these pregnant women gained within the IOM-recommended level while about $60 \%$ had lower or excessive weight gain.

Previous studies have shown that factors, such as pre-pregnancy BMI, height, age, number of prenatal visits, income, smoking, 
and infant's sex are associated with GWG (Alonso et al., 2011). Despite the important contribution of maternal nutritional status and dietary factors to weight gain during pregnancy, only a few studies have determined the influences of these factors on maternal weight gain while most studies have focused on the relationship between intake of nutrients and birth outcomes (Hediger et al., 2010).

Burdette et al, (2014) stated that physical daily activity and rational diet constitute vital determinants of health. However, a tendency to reduce physical activity level in favor of passive ways of spending free time have been observed recently, along with unfavorable nutritional behaviors, such as non-varied diets, deficient in minerals and vitamins (Rasmussen et al ; 2014). Usually, such diets are based on high-calorie products with low nutritional values ( Moke et al , 2011).

The activities performed by the rural women are dichotomized into house hold activities and income generating activities. (Coco, 2012). In Egypt, domestic activities consume a considerable amount of women's time and energy, especially in rural areas as electrical appliances are not yet in common use (Bellamy, 2011). Domestic work mainly involves cooking, washing utensils and clothes, and sweeping the floor (Pickles, 2010).

Seiga-Riz et al (2010) stated that nurses usually report feeling anxious or worried about discussing weight with pregnant women as weight can be very sensitive topic for many women, in particular during pregnancy when weight gain is investable. The nurse should weigh every woman at the start of pregnancy during the initial antenatal visit and then repeatedly during each visit as a matter of routine ( Sevenhuysen et al ., 2012).

The nurse can explain that maternal weight gain consists of increments in the weight of many tissues, not just the growing fetus (Abrahams et al., 2009). Nevertheless,

The nurse should not focus unduly on weight gain because doing so could result in feeling of stress and guilt in the woman who does not follow the preferred pattern of gain (Alters et al., 2010).

\section{Purpose}

The aim of this study is to assess the relationship between sociodemographics, dietary intake and activities of daily living with gestational weight among pregnant women in a rural area.

\section{Research question:}

- Is there a relationship between sociodemographics and gestational weight among pregnant women in a rural area?

- Is there a relationship between dietary intake and gestational weight among pregnant women in a rural area?

- Is there a relationship between activities of daily living and gestational weight among pregnant women in a rural area?

\section{Methods}

Research design: Descriptive design (a subtype of the non-Experimental design) was used to the present study participants: total number 324 women who attended maternal and child health care centers

Setting: this study was conducted at Maternal and Child Health Centers at Shebin El-Kom,Menoufia (Quibli maternal and child health care center and Bahari maternal and child health care center)

\section{Data collection tools}

A structured interview questionnaire was used for data collection.

\section{Part I:}

It involved structured questionnaire about sociodemographic data that included name, age, educational level, occupation, and income.

\section{Part II:}

Structured tool about current pregnancy that involved Number of pregnancies, Duration of current pregnancy per weeks and Presence of any complications during this pregnancy.

\section{Part III:}

Structured tool about Data about current Dietary Intake that consisted of Number of 
daily meals, Types of daily food, Types of in between meals, Methods of cooking foods and Three days' 24-hour recalls.

\section{Part IV:}

It involved activities of daily living that consisted of indoor activities of daily living, outdoor activities of daily living, work activities of daily living, work daily activities and field daily activities.

\section{Part V:}

Structured tool about anthropometric measurements the included Weight before Pregnancy in $\mathrm{kg}$, Height in $\mathrm{cm}$, Basal Metabolic Index (BMI) and Current Weight in $\mathrm{kg}$.

\section{Validity:}

The validity of the tools was ascertained by jury of five of qualified experts ( Two experts from Faculty of Nursing, two physician from obstetrics and gynecology department at the Faculty of Medicine ,and a physician from Quibli maternal and child health care center.

\section{Reliabilit:}

Test -retest reliability was applied by the researcher for testing the internal consistency of the instruments. It is the administration of the same instruments to the same participants under similar condition on two or more occasions scores from repeated testing were compared.

\section{Methods:}

An official permission to carry out the study was obtained from the directors of selected centers after submitting an official letter from the Dean of the Faculty of nursing at El-Menoufia University explain the purpose of the study and methods of data collection. Meetings were conducted first with the director $\mathrm{s}$ of the centers to obtain permission for conducting the research explaining the aim of the study.

\section{Ethical consideration:}

For ethical consideration, all women were informed that the information they provided during the study would be kept confidential and used only for statistical purpose and after finishing the study. The findings will be presented as a group data with no personal participant's information remained. Each woman was informed that participation in the study was voluntary, and that she could withdraw from the study whenever she decided to and each one was given the opportunity to freely refuse participation. They were free to ask any question about the study details

\section{Pilot study}

Piloting was conducted to test the applicability of the tools, the feasibility of the study and to estimate the time needed for data collection. It was conducted on $10 \%$ of the total sample (32 women). On the basis of the pilot study results; the researcher rephrased some questions and sentences then set the final fieldwork schedule.

\section{Data collection procedure:}

\section{Preparatory phase:}

An extensive review of all data related to the study was done including electronic thesis and dissertation, available books, articles and periodicals. A review of related literature to formulate the knowledge basis relevant to the study area was also done.

\section{Implementation phase (data collection):}

Data collection started from January 2015 until end of May 2015. The researcher collected the data in the class room present in the $\mathrm{MCH}$ during the morning at Three days/ week from 9A.M to12 A.M . About Seven to Eight pregnant women were interviewed per day, each woman took about 15 to 20 minutes to explain and complete the interview questionnaire

\section{Statistical design:}

Upon completion of data collection, each answer sheet was coded and scored. The researcher coded the data into a coding sheet so that data could be prepared for computer use. Data was statistically analyzed using Statistical Package for Social Sciences (SPSS) (version 16.0); (SPSS Inc., Chicago, IL, USA) and SAS (version 9.1) for Windows (SAS Institute 
Inc., Cary, NC, USA) software. Descriptive statistics were computed for all variables. The associations of independent predictors with GWG model (binary logistic and cumulative logit models) were expressed as odds ratios (OR) with $95 \%$ confidence interval $(\mathrm{CI})$.. Level of significance was at $\mathrm{p}<0.05$.

\section{Results}

Table (1): Maternal Characteristics are shown in table (1).The mean age of the women was $26.61 \pm 4.71$ years, Nearly most of the pregnant women completed their secondary education $(69.8 \%)$. The majority of the women are housewives. Regarding the income, majority of the women had enough income $(92.6 \%)$ and $6.8 \%$ had not enough income. Based on pre- pregnancy BMI,50\% of the women were overweight before pregnancy

Table (2) indicated the logistic regression models for factors relating to inadequate, adequate, and excessive gestational weight gain. The first model shows that women with inadequate weight gain, compared to the adequate group, had lower age $(\mathrm{OR}=0.892$, 95\% CI 0.806-0.987), prepregnancy BMI $(\mathrm{OR}=0.812,95 \%$ CI 0.723 0.912 ), and care about children or elders (OR=0.997, 95\% CI 0.994-0.999). The second model indicates that women with inadequate weight gain, compared to excessive group, had lower pre-pregnancy BMI $(\mathrm{OR}=0.629,95 \% \mathrm{CI} 0.532-0.745)$ and energy in intake $\mathrm{OR}=(0.998,95 \%$ CI 0.997-0.999) than excessive group. In the third model, pregnant women in the group of adequate weight gain had lower prepregnancy $\mathrm{BMI}(\mathrm{OR}=0.840,95 \%$ CI $0.777-$ 0.909).

Part (3) represented the following factors to be significantly associated with increasing GWG: age $(\mathrm{OR}=1.083,95 \% \mathrm{CI}$ $1.016-1.153)$ and pre-pregnancy BMI $(\mathrm{OR}=1.507, \quad 95 \% \quad$ CI $1.182-1.349$; $\mathrm{p}<0.0001)$. In other words, pregnant women with higher age and higher pre-pregnancy BMI were more likely to have higher GWG.

Fig 1 Clarified the time spent to care about children or elders and gestational weight.

Table (1): Background characteristics of pregnant women $(\mathrm{N}=324)$

\begin{tabular}{|l|c|c|}
\hline Characteristics & $\mathrm{No}(\%)$ & Mean \pm SD \\
\hline Age & $113(36.7)$ & $26.61 \pm 4.71$ \\
$18-24$ & $111(36.0)$ & \\
$25-29$ & $84(27.3)$ & \\
$30-34$ & & \\
\hline Level of Education & $4(1 \%)$ & \multirow{2}{*}{$10.99 \pm 3015$} \\
Illiterate & $38(11.7 \%)$ & \\
Read and write & $226(69.8)$ & \\
Secondary & $56(17.3)$ & \\
University & $110(30.9 \%)$ & $554.66 \pm 37.97$ \\
\hline Occupation & $214(69.1 \%)$ & \\
Working & & \\
Housewife & $290(92.6 \%)$ & $445.25 \pm 299.70$ \\
\hline Income & $34(6.8 \%)$ & \\
Enough & $96(29.6 \%)$ & \\
not Enough & $74(22.8 \%)$ & $323.21 \pm 122.20$ \\
\hline Number of pregnancies & $134(44.4)$ & \\
Once & $20(3.1 \%)$ & \\
Twice & $10(3.1 \%)$ & \\
Three times & $91(29.6 \%)$ & $63.54 \pm 10.86$ \\
More than Three times & $162(50 \%)$ & \\
\hline Basal Metabolic Index (BMI) & $51(17.3)$ & \\
Underweight & & \\
Normal Weight & & \\
Over weight & & \\
Obese & & \\
\hline
\end{tabular}


Rania E.El-Gobashy, Dalal K.Eshra, Inas k.Aly" Relationship between ..."

Table (2): Adjusted odd ratios (OR) for factors associated with inadequate, adequate and excessive gestational weight gain

\begin{tabular}{|c|c|c|c|}
\hline \multicolumn{4}{|c|}{ Gestation weight gain $(\mathrm{GWG})$ or Variable $(95 \% \mathrm{CI})$} \\
\hline Inadequate VS Adequate & \multicolumn{2}{|c|}{ Inadequate VS Excessive } & Adequate VS \\
\hline Age (years) & $\begin{array}{c}0.882 \\
(0.806-0.987)\end{array}$ & $\begin{array}{c}0.882 \\
(0.779-1.000)\end{array}$ & $\begin{array}{c}0.974 \\
(0893-1.040)\end{array}$ \\
\hline Number of pregnancy & $\begin{array}{c}1.583 \\
(0.859-2.882)\end{array}$ & $\begin{array}{c}1.368 \\
(0.628-2.938)\end{array}$ & $\begin{array}{c}1.071 \\
(0.666-1.691)\end{array}$ \\
\hline Pre-pregnancy BMI (Kg/m2) & $\begin{array}{c}0.813 \\
(0.723-0 . .912)\end{array}$ & $\begin{array}{c}0.63 \\
(0.532-0.745)\end{array}$ & $\begin{array}{c}0.841 \\
(0.777-0.929)\end{array}$ \\
\hline Number of meals per day & $\begin{array}{c}0.998 \\
(0.876-1134)\end{array}$ & $\begin{array}{c}0.988 \\
(0.849-1.147)\end{array}$ & $\begin{array}{c}0.949 \\
(0.861-1.043)\end{array}$ \\
\hline Eating meals regularly & $\begin{array}{c}1.002 \\
(0887-1018)\end{array}$ & $\begin{array}{c}1003 \\
(0883-1022)\end{array}$ & $\begin{array}{c}0995 \\
(0982-1009)\end{array}$ \\
\hline Energy (Kcal) & $\begin{array}{c}0.998 \\
(0.998-1.000)\end{array}$ & $\begin{array}{c}0.997 \\
(0.997-0.999)^{*}\end{array}$ & $\begin{array}{c}1.000 \\
(0.999-1.001)\end{array}$ \\
\hline Fat $(\mathrm{g})$ & $\begin{array}{c}1.002 \\
(0987-1.017)\end{array}$ & $\begin{array}{c}1.002 \\
(0.983-1.021)\end{array}$ & $\begin{array}{c}0.996 \\
(0.983-1.009)\end{array}$ \\
\hline Protein $(g)$ & $\begin{array}{c}0.988 \\
(0.974-1.004)\end{array}$ & $\begin{array}{c}0.988 \\
(0.971-1.007)\end{array}$ & $\begin{array}{c}0.996 \\
(0.993-1.001)\end{array}$ \\
\hline Carbohydrate & $\begin{array}{c}1.001 \\
(0.996-1.006)\end{array}$ & $\begin{array}{c}1.001 \\
(0.996-1.007) \\
\end{array}$ & $\begin{array}{c}0.997 \\
(0.993-1.001) \\
\end{array}$ \\
\hline Way to the market & $\begin{array}{c}1.002 \\
(0.887-1.018)\end{array}$ & $\begin{array}{c}1.003 \\
(0.883-1.022)\end{array}$ & $\begin{array}{c}0996 \\
(0.983-1.009)\end{array}$ \\
\hline $\begin{array}{l}\text { Care about children and } \\
\text { elders }\end{array}$ & $\begin{array}{c}1.001 \\
(1.00-1.003) \\
\end{array}$ & $\begin{array}{c}1.002 \\
(1.000-1.004) \\
\end{array}$ & $\begin{array}{c}1.000 \\
(0.999-1.001) \\
\end{array}$ \\
\hline $\begin{array}{l}\text { Distance from the field to the } \\
\text { house }\end{array}$ & $\begin{array}{c}0.878 \\
(0.998-1.000) \\
\end{array}$ & $\begin{array}{c}0.887 \\
(0.997-0.999)^{*} \\
\end{array}$ & $\begin{array}{c}1.000 \\
(0.988-1.001) \\
\end{array}$ \\
\hline $\begin{array}{l}\text { Time spent Ploughing and } \\
\text { harvesting the field }\end{array}$ & $\begin{array}{c}1.002 \\
(0.988-1.017)\end{array}$ & $\begin{array}{c}1.002 \\
(0.988-1.021)\end{array}$ & $\begin{array}{c}0.997 \\
(0.984-1.009)\end{array}$ \\
\hline $\begin{array}{l}\text { Time spent making cheese } \\
\text { and milk productions }\end{array}$ & $\begin{array}{c}0.999 \\
(0974-1004)\end{array}$ & $\begin{array}{c}0.999 \\
(0.971-1.007)\end{array}$ & $\begin{array}{c}0.997 \\
(0.993-1.001)\end{array}$ \\
\hline
\end{tabular}

Table (3)Factors associated with gestational weight gain (Cumulative Logit Model Ordinal Responses)

\begin{tabular}{|l|l|l|l|}
\hline Variable & OR & $95 \% \mathrm{VI}$ & P Value \\
\hline Age (years) & 1.083 & $(1.016-1.153)$ & 0.0137 \\
\hline Number of pregnancy & 1.507 & $(1.182-1.349)$ & $<00001$ \\
\hline Pre-pregnancy BMI $(\mathrm{Kg} / \mathrm{m} 2)$ & 1.042 & $(0.963-1.124)$ & 0.3019 \\
\hline Number of meals per day & 0.762 & $(0.519-1.117)$ & 0.1637 \\
\hline Eating meals regularly & 1.000 & $(0.989-1.000)$ & 0.2113 \\
\hline Energy (Kcal) & 1.000 & $(1.000-1.001)$ & 0.2543 \\
\hline Fat $(\mathrm{g})$ & 1.002 & $(0.991-1.012)$ & 0.7449 \\
\hline Protein (g) & 1.002 & $(0.993-1.012)$ & 0.6366 \\
\hline Carbohydrate & 1.002 & $(0.998-1.005)$ & 0.3161 \\
\hline Way to the market & 1.022 & $(0.963-1.124)$ & 0.3019 \\
\hline Care about children and elders & 1.000 & $(0.999-1.000)$ & 0.2213 \\
\hline Distance from the field to the house & 0.742 & $(0.509-1.117)$ & 0.1637 \\
\hline Time spent Ploughing and harvesting the field & 1.000 & $(1.000-1.001)$ & 0.2443 \\
\hline Time spent making cheese and milk productions & 1.002 & $(0.981-1.012)$ & 07349 \\
\hline
\end{tabular}




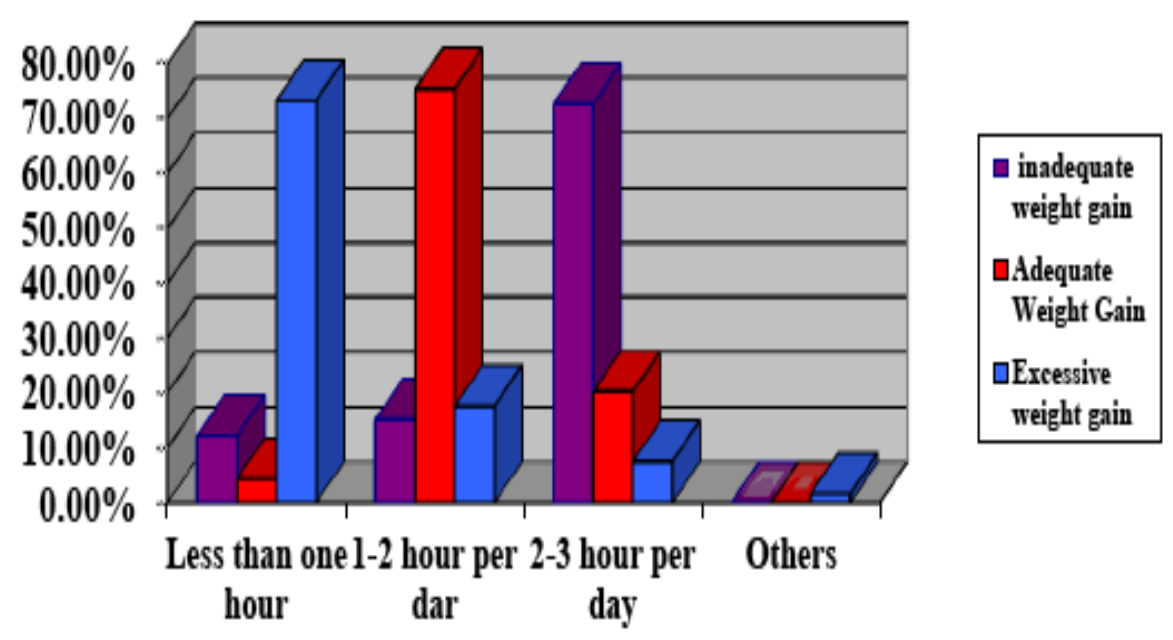

\section{Figure (1) Time spent to care about children or elders and gestational weight}

\section{Discussion}

Regarding the relationship between prepregnancy basal metabolic index and gestational weight gain (table 1), nearly half of overweight women before pregnancy had excessive weight during pregnancy as there was no difference between weight gain and level of BMI. This result is similar to that of Shapiro C, et al. (2011), and Choi S-K,et al. (2013) who studied Effect of maternal weight gain on infant birth weight mentioned that pre-pregnancy BMI is an important factor in determining GWG among pregnant women.

The result is also in accordance with Wiesman et al. (2011) who studied Preconception predictors of weight gain during pregnancy: prospective findings from the Central Pennsylvania Women's Health Study Women's Health Issues among 103 pregnant women, and reported that having pre-pregnancy BMI was a risk factor for excessive or insufficient weight gain during pregnancy respectively. The finding is contradicted by Kirchengast et al , ( 2010 ) who studied Factors affecting weight gain during pregnancy and the growth of the infant, and reported that Pre-pregnancy weight has been shown to be negatively associated with weight gain in poor and undernourished women
Regarding the relationship between diet recall and gestational weight gain(table 2), A few studies have examined the relationship between nutrient intake and weight gain, and the majority have focused primarily on other determinants as age, education, income, working status of inadequate weight gain. Although we expected some nutrient intakes to predict pregnancy weight gain in the cumulative logit model, only energy, fat , protein and carbohydrate intake were significant in binary logistic regression (between inadequate vs excessive group).

There was no significant difference in macronutrient intake between the weight gain groups; however, percentage of energy intake from protein was higher among excessive group compared to inadequate group.

Olafsdottir et al,(2012) who studied Determinants of weight gain in pregnant women attending a public prenatal care facility in Rio de Janeiro, Brazil: a prospective study reported that total energy intake was the highest among the group of excessive weight gain. They showed that absolute energy intake was also correlated with maternal weight gain $(\mathrm{r}=0.112, \mathrm{p}=0.024$ and the total amounts of protein, fat, and carbohydrate contributed to this weight gain. Scholl et al, ( 2009) who studied Maternal weight 
gain, diet and infant birth weight: correlations during adolescent pregnancy had indicated that maternal protein intake is positively associated with pregnancy weight gain.

The present study revealed significant increase in fiber intake among overweight women than adequate and inadequate weight. Contradicting with the present study Drehmer et al, ( 2011) who studied Socioeconomic, demographic and nutritional factors associated with maternal weight gain in general practices in Southern Brazil, and reported that BMI was not significantly correlated with reported fiber consumption( $\mathrm{r}=0.582$; $\mathrm{p}>0.05)$. This may be to reduce their obesity. This study is not supporting Olafsdottir et al, ( 2012) who studied Combined effects of maternal smoking status and dietary intake related to weight gain and birth size parameters, and found that the majority of pregnant women do not consume enough fiber. This contradiction can be rationalized that the rural areas depend on their diet on the green leafy vegetables that are rich in fibers

According to the present study, the results revealed that there was significant increase in protein consumption among overweight women than adequate and inadequate weight. This findings revealed that overweight women consume more than food rich in everything ( fiber and fat ) more frequently than those of adequate and inadequate weight. Also, they eat more portion of food. This findings harmonious with Yekta et al (2013), who studied The effect of pre-pregnancy body mass index and gestational weight gain on pregnancy outcomes in urban care settings in Urmia-Iran, reported that consumption of foods higher in protein may increase satiety, which results in fewer calories consumed. This may be due to protein - induced satiety appears to be of vital importance for weight loss and weight maintenance.

Contradicting with the present study Lagiou et al, ( 2013 ) who studied Diet during pregnancy in relation to maternal weight gain and birth size, reported that BMI was not significantly correlated with reported protein consumption $(\mathrm{r}=$ $0.0478 ; \mathrm{p}>0.05$ )

Regarding carbohydrate consumption, the present study reported that carbohydrate intake by overweight women was higher than adequate weight women.

Regarding the relationship between time spent ploughing and harvesting the field and gestational weight gain (table 3), the present study findings revealed that women who spend two to three hours ploughing and harvesting the field tend to gain less weight. This finding was supported by a study conducted by Rao et al , (2012) who found that most of the rural pregnant women perform ploughing and harvesting works as a belief that working till late pregnancy will lead to easier delivery.

\section{Conclusion}

This study found that, although approximately half of the pregnant women had adequate gestational weight gain, there was also a high proportion of pregnant women gaining excessive weight, particularly those who were overweight and obese. In addition, there was positive relationship between maternal characteristics such as age, prepregnancy basal metabolic index, energy intake and taking care of children with gestational weight gain. succeeded to answer the research questions.

\section{Recommendations}

Based on the findings of the present study, the following recommendations are suggested:

* Both inadequate and excessive weight gain among pregnant women should receive special attention as they pose a threat to mothers as well as infants.

* Pregnant women should be counseled on achieving the recommended gestational weight gain to prevent adverse maternal and prenatal outcomes.

* Women with pre-pregnancy normal weight with increased body mass index during pregnancy need special 
follow up and counseling during pregnancy.

\section{Reference}

Abrams B, Taffel SM (2010): Pregnancyrelated weight gain and retention: implications of the 2009 Institute of Medicineguidelines.Am J Public Health 83:1100-3

Ball K, Brown W, Crawford D (2012):Who does not gain weight? Prevalence and predictors of weight maintenance in young women. Int $\mathbf{J}$ Obes Relat Metab Disord 1570:8-26.

Bogale D, BMC public health (2014): 14:1076- 1471- 2458. 4-1076.

Bennett G, Wolin K(2013). Satisfied or unaware? Racial differences in perceived weight status. Int $\mathbf{J}$ Behav Nutr Phys Act 2006; 3: 40

Bertolotto A, Volpe L, Calianno A, Pugliese MC, Lencioni C, Resi Vet al (2010). Physical activity and dietary habits during pregnancy: effects on glucose tolerance. J Matern Fetal Neonatal Med 23:1310-4.

Caulfield LE, Witter FR, Stoltzfus RJ (2013). Determinants of gestational weight gain outside the recommended ranges among black and white women. Obstet Gynecol 87(5 Pt. 1):760-6 http://www.almasryalyoum.com/ne ws/details/862455

Dietz P, Callaghan W, Cogswell M, Morrow B, Ferre C, Schiev(2011) Combined effects of pre-pregnancy body mass index and weight gain during pregnancy on the risk of preterm delivery. Epidemiology 2006; 17: 170-177.Missailidisk, Debre, (2011): Female genital mutilation in eastern Ethiopia, pp 137-138-10-1016/50140.

Gray-Donald K, Robinson E, Collier A, David K, Renaud L, Rodrigues S (2013): Intervening to reduce weight gain in pregnancy and gestational diabetes mellitus in Cree communities: an evaluation.

Hernandez-Cordero S, Neufeld LM, Garcia-Guerra A, Aburto NJ (2015). Physical activity during pregnancy and early postpartum in Mexican women.FASEB J;22(Suppl):679.3. 1679.3 ,

Jeffery R(2012). Bias in reported body weight as a function of education, occupation, health and weight concern. Addict Behav 1996; 21: 217-222. Nour, N. M., (2008): Female genital cutting: a need reform. Obstetric Gvnecol; 101:1051-2.

Maddah M, Karandish M, Mohammadpour-Ahranjani B, Neyestani TR, Vafa R, Rashidi A(2015). Social factors and pregnancy weight gain in relation to infant birth weight: a study in public health centers in Rasht, Iran.

Olafsdottir AS, Skuladottir GV, Thorsdottir I, Hauksson A, Steingrimsdottir L(2013). Combined effects of maternal smoking status and dietary intake related to weight gain and birth size parameters. BJOG; 163;168

Sevenhuysen GP, Gross U(2011): Documenting the reasons people have for choosing their food. Asia Pac J ClinNutr 2008, 12:30-37.

Siega-Riz AM, Evenson KR, Dole N.P(2013) pregnancy-related weightgain — a link to obesity? Nutr Rev 2004;62(7 Pt. 2):S105-11

Yekta Z, Ayatollahi H, Porali R, Farzin A(2012). The effect of pre-pregnancy body mass index and gestational weight gain on pregnancy outcomes in urban care settings in UrmiaIran.BMC Pregnancy Childbirth 